\title{
Populasi, Biomassa dan Jenis Cacing Tanah pada Lahan Sayuran Organik dan Konvensional di Bedugul
}

\author{
ARFITA TRI MAYASARI, ANAK AGUNG ISTRI KESUMADEWI*), DAN \\ NI LUH KARTINI
}

\author{
Program Studi Agroekoteknologi, Fakultas Pertanian, Universitas Udayana \\ Jalan P.B. Sudirman, Denpasar, Bali. \\ ${ }^{*}$ E-mail: aai-kesumadewi@live.com
}

\begin{abstract}
Population, Biomass, and Types of Earthworm on Organic and Conventional Vegetable Land in Bedugul. Earthworm is an important indicator of soil fertility. The type of earthworm closelly associated with soil management system. This research aims to determine the population, biomass, and earthworms type that had been done on organic and conventional vegetable ecosystem in Bedugul from December 2017 until March 2018. The purposive research sites were located in Baturiti Village and Candikuning Village for organic and conventional vegetable systems, respectively. The research area was clustered following Randomized Block Design into three group sites and devided based on organic and conventional system as the first factor. The second factor was soil depth $(0-10$, 10-20 and 20-30 cm) that nested on cultivation system. Calculation of collected earthworm was done in situ while their morphological identification was done at The Soil Science and Environment Laboratory, Faculty of Agriculture,Udayana University.The results confirmed that earthworm population and biomass were affected by cultivation system but the values were not significantly difference among soil depths. The population and biomass of earthworm found in organic soils were two times higher than those in conventional land. Earthworms population in organic field ranged from 66.67 to $89.33 \mathrm{~m}^{-2}$ and on conventional land ranged from 16.00-45.33 $\mathrm{m}^{-2}$. The weight of earthworm biomass on organic land ranged from 1.00-1.93 $\mathrm{g}$ and on conventional land ranged from 0.03-0.06 $\mathrm{g}$. The type of worm acquired on organic soil was Lumbricus terrestris and on conventional land was Pontoscolex corethrurus. We can summary from this research that cultivation systems highly influence the community of earthworm.
\end{abstract}

Keywords: earthworm, organic, conventional, Lumbricus terrestris, Pontoscolex corethrurus

PENDAHULUAN

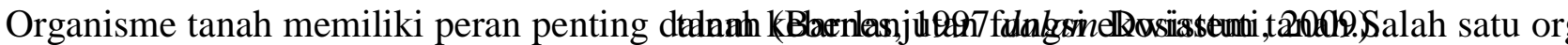
al., 1991).Cacing tanah berperan sangat besar dalam perbaikan kesuburan tanah melalui pembentukan humus, menggabungkan bahan yang membusuk pada lapisan tanah bagian atas, dan mempengaruhi kemantapan agregat

Cacing tanah dikelompokkan menjadi tiga, yaitu cacing epigeik (little dwellers), cacing endogeik (shallow soil dwelling), dan anecik (deep burrowers) (Bouche, 1977). 


\section{ARFITA TRI MAYASARI. et al. Populasi, Biomassa dan Jenis Cacing Tanah pada Lahan...}

Menurut Bouche (1977), cacing epigeik hidup di permukaan tanah atau bagian atas tanah dan memakan sampah organik yang masih kasar serta sejumlah sampah yang belum terurai. Cacing tanah endogeik hidup di dalam tanah yang lebih dalam dengan membuat liang horizontal yang bercabang ke dalam dan memakan tanah serta bahan organik. Cacing tanah anecik hidup di dalam sistem liang vertikal yang lebih permanen yang dapat meluas beberapa meter ke dalam tanah dan dapat ditemukan di dalam liang yang dangkal atau dalam tergantung pada kondisi tanah.

Cacing tanah sangat sensitif terhadap gangguan lingkungan terutama bahan agrokimia seperti pestisida. Residu pestisida di dalam tanah dapat menurunkan secara laten pertumbuhan dan reproduksi cacing tanah (Yuliprianto, 2009). Selain itu, praktik pertanian modern dilaporkan mengubah kelimpahan dan komposisi komunitas cacing tanah (Curry, et al, 2002).Menurut Edwards dan Bohlen (1996), populasi cacing tanah menurun sampai dengan $70 \%$ setelah tanah dibudidayakan selama 5 tahun dan tersisa hanya $11-16 \%$ pada tahun ke25. Jumlah populasi cacing tanah lebih tinggi pada lahan yang dikelola secara organik dibandingkan lahan alami dan terintegrasi (Köhler et.al., 2014). Nuril, dkk. (1999) menyatakan bahwa, lahan pertanian intensif pada umumnya memiliki populasi cacing tanah yang lebih rendah salah satunya karena perubahan sifatsifat tanah. Perubahan sifat tanah dapat menghilangkan populasi cacing tanah tertentu dan menyebabkan munculnya spesies baru (Smetak et al., 2007).

Populasi cacing tanah pada lahan pertanian di Indonesia sangat beragam.
Cacing tanah paling banyak ditemukan pada kedalaman 0-15 cm dan hanya sedikit jumlahnya pada kedalaman $>15 \mathrm{~cm}$ (Subinkalu et al., 2015).Populasi cacing tanah pada lahan sawah organik di Jawa Tengah berkisar antara $24-1.145$ ekor per $\mathrm{m}^{2}$, sedangkan pada sawah konvensional berkisar antara 16-24 ekor per $\mathrm{m}^{2}$ (Wijayanti, 2007) Populasi cacing tanah yang jauh lebih tinggi ditemukan oleh Jayanthi et al. (2014) pada lahan sayuran di daerah Karo Propinsi Sumatera Utara yaitu 128.000 ekor per $\mathrm{m}^{2}$ pada lahan organik dan 73.600 ekor per $\mathrm{m}^{2}$ pada lahan konvensional. Jenis cacing tanah yang terdapat pada sistem pertanian tersebut adalah Ponthoscolexcorethrurus, Amynthas sp, Megascolex sp, dan Pheretima sp (Jayanthi dkk., 2014).

\section{BAHAN DAN METODE}

Penelitian ini telah dilakukan pada bulan Desember 2017 - Maret 2018.Lokasi penelitian adalah lahan sayuran organik di Desa Batunya dan lahan sayuran konvensional di Desa Candikuning.

Peralatan yang diperlukan dalam penelitian ini adalah sebagai berikut. Pengambilan sampel penelitian dilakukan dengan menggunakan cangkul, sarung tangan, sekop, ayakan berukuran $2 \mathrm{~mm}$, kantong, gelas plastik dan baki plastik, meteran, kertas label, serta alat tulis. Alat yang digunakan dalamanalisis tanah serta pengamatan morfologi dan pengukuran biomassa cacing tanah adalah ayakan 2 mm,mistar, kaca pembesar, mikroskop, ring sampel, pH meter, makro kjeldahl, oven, neraca analitik, tin, dan peralatan gelas.Dokumentasi dilakukan dengan kamera, sedangkan tabulasi data hasil 
penelitian dilakukan dengan komputer dan perangkat lunak pengolah data.Bahan penelitian yang digunakan ialah cacing tanah lokal dan tanah yangdiambil dari lahan penelitian serta bahan kimia untuk analisis sifat-sifat tanah di laboratorium.

\section{Penelitian dilakukan dengan} menggunakan rancangan lingkungan acak kelompok (RAK) yang terdiri dari 3 kelompok (Gambar 1). Penelitian dirancang dengan rancangan faktor tersarang yaitu faktor kedua (kedalaman tanah) tersarang pada faktor pertama (sistem
budidaya).Sistem budidayaterdiri dari 2 taraf yaitu sistem budidaya sayuran organik (O) dan sistem budidaya sayuran konvensional (K). Faktor kedua adalah kedalaman tanah yang terdiri dari 3 jenis kedalaman tanah yaitu 0-10 cm, 10-20 cm dan 20-30 cm. Lokasi penelitian dipilih secara purposivepada lahan budidaya sayuran organik dan konvensional di daerah Bedugul. Sampel tanah dan cacing diambil secara acak lalu dikompositkan pada tingkat kedalaman tanah dalam kelompok.
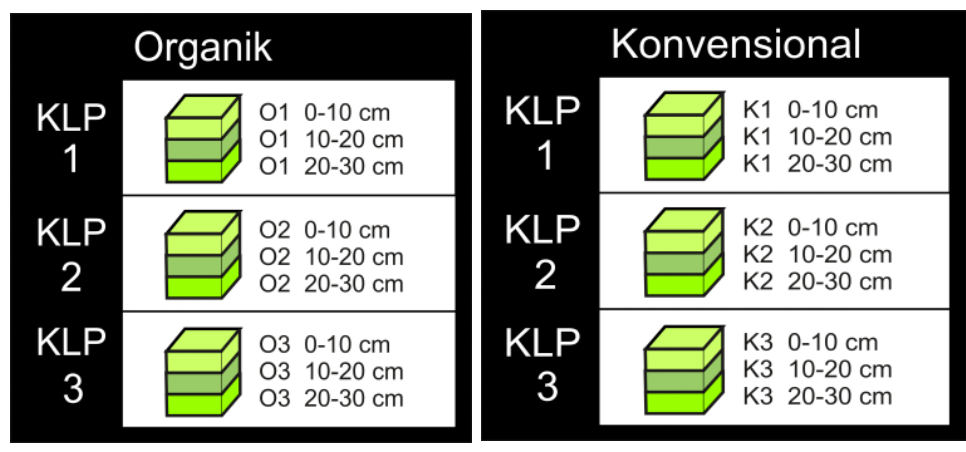

Gambar 1. Ilustrasi titik sampel dalam minipit

\section{Tahapan Pelaksanaan Penelitian}

Penelitian dilakukan dengan mengikuti tahapan berikut (Gambar 2). Lokasi penelitian dipilih secara purposif pada lahan budidaya sayuran organik dan konvensional di daerah Bedugul. Sampel tanah dan cacing diambil dengan metode minipit berukuran 0,5 x 0,5 x 0,5 m (Gambar 3; Puslitanak, 2004). Tiga minipit dibuat untuk setiap satuan penelitian dengan menggunakan cangkul. Tanah pada masing-masing lapisan minipit diambil dengan menggunakan sekop dan langsung diayak dengan ayakan berdiameter $2 \mathrm{~mm}$. Cacing tanahyang terdapat pada kedalaman $0-10 \mathrm{~cm}, 10-20 \mathrm{~cm}$, dan20-30 cmdari ketiga minipit dalam 1 satuan percobaan dikompositkan laludimasukkan ke dalam gelas plastik yang telah diberi label. 
ARFITA TRI MAYASARI. et al. Populasi, Biomassa dan Jenis Cacing Tanah pada Lahan...

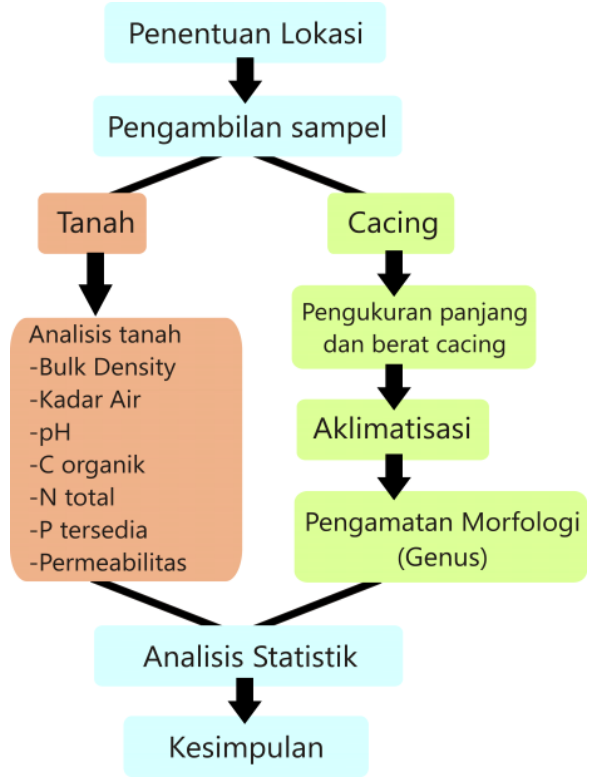

Gambar 2. Bagan alir proses penelitian

Sampel tanah terganggu dan tidak terganggu dikeringanginkan di laboratorium, terganggu juga diambil dari masing-masing diayak menggunakan ayakan berukuran 2 lapisan tersebut.Sampel tanah tidak $\mathrm{mm}$, dan kemudian digunakan untukanalisis terganggu diambil menggunakan ring sampel beberapa sifat tanah.

untuk mengukurBulk density dan

permeabilitas, sedangkan sampel tanah

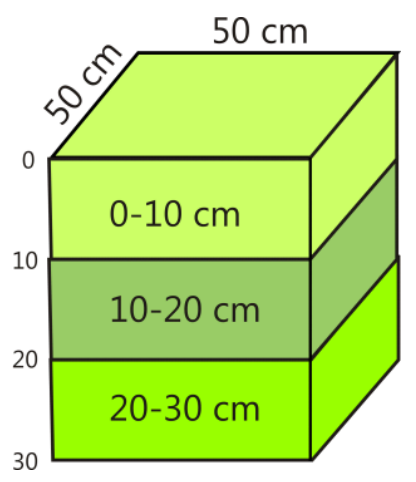

Gambar 3.Minipit dan kedalaman tanah

Parameter aktual cacing tanah diukur di jenis cacing tanah. Kepadatan populasi lapangan segera setelah cacing tanah cacing (KPC) tanah dihitung dengan metode diperoleh. Parameter aktual tersebut adalah handsorting menggunakan rumus (Kalu et kepadatan populasi, panjang, biomassa dan al.,2015): 


\section{KPC $\left(\mathrm{ekor} / \mathrm{m}^{2}\right)=\underline{\text { Jumlah cacing tanah/luas area sampel }}$}

Panjang cacing tanah diukur dengan mistar dan dinyatakan dalam satuan sentimeter $(\mathrm{cm})$. Biomassa cacing tanah (BCT) diduga dengan persamaan alometri panjangbiomassa yang diukur dengan rumus berikut (Hale et al., 2004):

\section{Ln BCT $(\mathrm{g})=$ 2,2853 x Ln panjang $(\mathrm{cm})$ - 11,9047}

Setiap cacing tanah dibedakan atas cacing muda dan dewasa berdasarkan perbedaan warna klitelum. Lumbricus dewasa memiliki klitelum berwarna kuning. Jumlah masingmasing kelompok cacing tersebut dihitung dan dicatat.Data masing -masing parameter yang diperoleh dianalisis dengan ANOVA (Analysis of Varian) dengan menggunakan software Costat. ANOVA yang menunjukkan pengaruh nyata faktor pada parameter yang diuji dilanjutkan dengan analisis Beda Nyata Terkecil pada taraf 5\% untuk mengetahui perbedaan faktor yang diteliti pada parameter tersebut. Keeratan hubungan antar parameter diukur dengan uji korelasi menggunakan software SPSS (IBM Inc, 2010).

\section{HASIL DAN PEMBAHASAN}

Rangkuman signifikansi faktor yang dikaji dalam penelitian ini disajikan pada Tabel 1. Pengaruh sistem budidaya nyata terhadap seluruh parameter yang diamati tetapi pengaruh kedalaman tanah tidak berbeda nyata.Tabel 2-3menunjukkan, bahwa KPC, biomassa, N-total, P-tersedia, nilai $\mathrm{pH}$, berat volume $(\mathrm{BV})$, dan permeabilitas tanah dipengaruhi sangat nyata oleh faktor sistem budidaya $\quad(\mathrm{P}<0,01)$, sedangkan faktor kedalaman tanah tidak menyebabkan perbedaan nyata terhadap parameter yang diamati.
Tabel 1. Signifikansi

\begin{tabular}{lcc}
\hline Parameter & \multicolumn{2}{c}{ Signifikansi } \\
\cline { 2 - 3 } & $\begin{array}{c}\text { Sistem } \\
\text { Budidaya }\end{array}$ & $\begin{array}{c}\text { Kedalaman } \\
\text { tanah }\end{array}$ \\
\hline KPC & $* *$ & Ns \\
\hline Biomassa & $* *$ & Ns \\
\hline N-Total & $* *$ & Ns \\
\hline P Tersedia & $* *$ & Ns \\
\hline C-Organik & Ns & Ns \\
\hline BV & $*$ & Ns \\
\hline pH & $* *$ & Ns \\
\hline Permeabilitas & $* *$ & Ns \\
\hline $\begin{array}{c}\text { Keterangan : } \\
\text { * : nyata }\end{array}$ \\
** : sangat nyata \\
Ns : non signifikan
\end{tabular}

Hasil penelitian menunjukkan, bahwa sifat-sifat tanah seperti kadar N-total, Ptersedia, C-organik, nilai $\mathrm{pH}$, berat volume (BV), dan permeabilitas tanah berbeda antar sistem budidaya tetapi umumnya tidak berbeda antarkedalaman tanah pada masingmasing sistem budidaya.Tanah pada sistem budidaya organik memiliki tingkat kesuburan yang lebih tinggi dibandingkan dengan konvensional (Tabel 2). Tidak adanya perbedaansifat-sifat tanah yang signifikan antar kedalaman diduga disebabkan oleh intensitas pengolahan tanah dan aktivitas pedoturbasi oleh makrofauna tanah. 
ARFITA TRI MAYASARI. et al. Populasi, Biomassa dan Jenis Cacing Tanah pada Lahan...

Tabel 2. Sifat Tanah pada Lahan Sayuran Organik dan Konvensional

\begin{tabular}{llcccccc}
\hline $\begin{array}{c}\text { Sistem } \\
\text { Budidaya }\end{array}$ & \multicolumn{1}{c}{$\begin{array}{c}\text { Kedalaman } \\
(\mathbf{c m})\end{array}$} & $\begin{array}{c}\mathbf{N}- \\
\text { total } \\
(\mathbf{\%})\end{array}$ & $\begin{array}{c}\text { P- } \\
\text { tersedia } \\
(\mathbf{p p m} \\
\left.\mathbf{P}_{2} \mathbf{O}_{\mathbf{5}}\right)\end{array}$ & $\begin{array}{c}\mathbf{C}- \\
\text { Organik } \\
(\mathbf{\%})\end{array}$ & $\begin{array}{c}\text { Berat } \\
\text { volume } \\
\left(\mathbf{g} / \mathbf{m}^{3}\right)\end{array}$ & $\mathbf{p H}$ & $\begin{array}{c}\text { Permeabilitas } \\
(\mathbf{m l} / \mathbf{m e n i t})\end{array}$ \\
\hline \multirow{3}{*}{ Organik } & $0-10$ & 0.48 & 370.41 & 5.51 & 0.96 & 6.85 & \\
& $10-20$ & 0.49 & 267.20 & 5.52 & 0.86 & 6.78 & \\
& $20-30$ & 0.34 & 210.33 & 5.45 & 0.85 & 6.89 & \\
Konvensional & $0-10$ & 0.28 & 219.41 & 4.93 & 1.04 & 6.50 & \\
& $10-20$ & 0.30 & 193.99 & 4.71 & 1.05 & 6.48 & \\
\hline Rata-rata pada Sistem Organik & 0.23 & 162.42 & 4.30 & 1.01 & 6.44 & \\
Rata-rata pada Sistem Konvensional & $\mathbf{0 . 4 3 a}$ & $\mathbf{2 9 9 . 3 1 a}$ & $\mathbf{3 . 0 1 a}$ & $\mathbf{0 . 8 6 b}$ & $\mathbf{6 . 8 1 a}$ & $\mathbf{3 5 . 9 3 a}$ \\
\hline
\end{tabular}

Ket : Angka bercetak tebal yang diikuti oleh huruf yang sama pada kolom yang sama berbeda tidak nyata pada taraf $5 \%$ uji BNT.

Berdasarkan sifat-sifat tanah yang diukur, tanah pada kedua lahan pertanian tergolong subur. Tingkat kesuburan tanah lebih tinggi pada lahan organik. Kadar Ntotal tanah pada lahan organik berkisar antara $0.34-0.48 \%$ (sedang) sedangkan pada lahan konvensional sebesar $0.23-0.30 \%$ (sedang).Kadar P-tersedia pada lahan organik berkisar antara 210.33-370.41 ppm $\mathrm{P}_{2} \mathrm{O}_{5}$ (tinggi) dan pada lahan konvensional berkisar antara 162.42-219.41 ppm $\mathrm{P}_{2} \mathrm{O}_{5}$ (tinggi). Kadar C-organik pada lahan organik berkisar antara $5.45-5.52 \%$ (sangat tinggi) sedangkan pada lahan konvensional berkisar antara 4.30-4.93\% (tinggi). Nilai berat volume tanah pada lahan organik berkisar antara 78.83-90.08 g/m $\mathrm{m}^{3}$ dan pada lahan konvensional berkisar antara 93.16$97.55 \mathrm{~g} / \mathrm{m}^{3}$. Nilai $\mathrm{pH}$ pada lahan organik berkisar antara 6.78-6.89 (agak masam) sedangkan pada lahan konvensional 6.446.50 (agak masam).Nilai rata-rata permeabilitas pada lahan organik adalah
$35.93 \mathrm{ml} / \mathrm{menit}$ (cepat) sedangkan pada lahan konvensional adalah $14.87 \mathrm{ml} / \mathrm{menit}$ (sedang).

Hasil penelitian menunjukkan bahwa populasi cacing tanah (KPC) dan biomassa cacing tanah nyata lebih tinggi pada lahan budidaya organik dibandingkan konvensional (Tabel 3). Nilai KPC pada lahan organik berkisar 66.67-89.33 ekor $/ \mathrm{m}^{2}$ dan pada lahan konvensional adalah 16.00-45.33 ekor $/ \mathrm{m}^{2}$. Jumlah populasi cacing tanah terbanyak pada lahan organik ditemukan pada kedalaman 0$10 \mathrm{~cm}\left(89.33 \mathrm{ekor} / \mathrm{m}^{2}\right)$ sedangkan pada lahan konvensional pada kedalaman 20-30 cm (45.33 ekor $/ \mathrm{m}^{2}$ ). Bobot biomassa cacing tanah pada lahan organik berkisar antara 1.00-1.93 g dan pada lahan konvensional berkisar antara 0.03-0.07 g. Jenis cacing tanah yang ditemukan pada lahan organik adalah L. terrestris sedangkan pada lahan konvensional adalah $P$. corethrurus (Tabel $3)$. 
Tabel 3. Populasi, Jenis,dan Biomassa Cacing Tanah pada Lahan Organik dan Konvensional

\begin{tabular}{llccl}
\hline $\begin{array}{c}\text { Sistem } \\
\text { Budidaya }\end{array}$ & \multicolumn{1}{c}{$\begin{array}{c}\text { Kedalaman } \\
(\mathbf{c m})\end{array}$} & $\begin{array}{c}\text { KPC } \\
\left(\mathbf{e k o r} / \mathbf{m}^{2}\right)\end{array}$ & $\begin{array}{c}\text { Biomassa } \\
(\mathbf{g})\end{array}$ & \multicolumn{1}{c}{ Jenis } \\
\cline { 2 - 4 } Organik & $0-10$ & 89.33 & 1.93 & \\
& $10-20$ & 64.00 & 1.71 & Lumbricus \\
& $20-30$ & 66.67 & 1.00 & terrestris \\
Konvensional & Rata-rata Organik & $\mathbf{7 3 . 3 3 a}$ & $\mathbf{1 . 5 4 a}$ & \\
& $0-10$ & 16.00 & 0.03 & \\
& $10-20$ & 30.67 & 0.07 & Pontoscolex \\
& $20-30$ & 45.33 & 0.06 & corethrurus \\
\hline
\end{tabular}

Ket:

KPC (Kepadatan Populasi Cacing) ekor $/ \mathrm{m}^{2}$

Angka bercetak tebal yang diikuti oleh huruf yang sama pada kolom yang sama berbeda tidak nyata pada taraf $5 \%$ uji BNT.

Berdasarkan data hasil analisis tanah diketahui bahwa lahan budidaya sayuran organik lebih subur dibandingkan dengan lahan konvensional. Kadar N-total, P-tersedia dan C-organik tanah pada lahan organik lebih tinggi dibandingkan dengan lahan konvensional (Tabel 2).Karakteristik tanah tersebut berhubungan dengan keberadaan cacing tanah. Kesuburan tanah yang lebih tinggi pada lahan organik nampaknya mendukung perkembangan populasi dan biomassa cacing tanah lokal. Dalam penelitian ini populasi cacing tanah lebih tinggi pada tanah yang dibudidayakan secara organik. Semakin banyak jumlah cacing tanah, maka semakin tinggi kesuburan tanah yang diindikasikan oleh ketersediaan unsur hara dan bahan organik yang lebih tinggi.Biomassa cacing tanah pada lahan budidaya organik berhubungan erat dengan P-tersedia $\quad\left(r^{2}=1.00\right) \quad$ (Tabel 4).Kenaikan biomassa cacing tanah disebabkan oleh melimpahnya sumber makanan untuk cacing tanah karena bahan organik pada media mempengaruhi kehidupan cacing tanah.

Tabel 4.Uji Korelasi pada Lahan Organik

\begin{tabular}{lcccccccc}
\hline & KPC & Biomassa & N & P & $\begin{array}{c}\text { C- } \\
\text { Organik }\end{array}$ & pH & Permeabilitas & BV \\
\hline KPC & 1 & .99 & .85 & .99 & .74 & .82 & .36 & .76 \\
Biomassa & .99 & 1 & .92 & $1.00^{* *}$ & .84 & .90 & .50 & .65 \\
N & .85 & .94 & 1 & .92 & .98 & $.98^{*}$ & .80 & .30 \\
P & .99 & $1.00^{* *}$ & .92 & 1 & .89 & .90 & .64 & .51 \\
C-Organik & .74 & .84 & .98 & .84 & 1 & .99 & .90 & .13 \\
pH & .82 & .90 & $.98^{*}$ & .90 & .99 & 1 & .83 & .25 \\
Permeabilitas & .36 & .51 & .80 & .51 & .90 & .83 & .25 & 1 \\
BV & .76 & .65 & .30 & .64 & .13 & .25 & -.33 & 1 \\
\hline
\end{tabular}

Keterangan :

* : korelasi positif nyata

** : korelasi positif sangat nyata 
ARFITA TRI MAYASARI. et al. Populasi, Biomassa dan Jenis Cacing Tanah pada Lahan...

Tabel 5.Uji Korelasi pada Lahan Konvensional

\begin{tabular}{lrrrrrrrr}
\hline & KPC & Biomassa & N & P & $\begin{array}{c}\text { C- } \\
\text { organik }\end{array}$ & pH & Permeabilitas & BV \\
\hline KPC & 1 & $.98^{*}$ & -.07 & -.72 & -.58 & $.98^{*}$ & -.89 & .61 \\
Biomassa & $.98^{*}$ & 1 & .00 & -.68 & -.53 & $1.00^{* *}$ & -.86 & .66 \\
N & -.07 & .00 & 1 & .74 & .85 & .00 & .52 & .75 \\
P & -.72 & -.68 & .74 & 1 & .98 & -.68 & .96 & .10 \\
C-Organik & -.58 & -.53 & .85 & .98 & 1 & -.53 & .89 & .29 \\
pH & $.98^{*}$ & $1.00^{* *}$ & .00 & -.68 & -.53 & 1 & -.86 & .66 \\
Permeabilitas & -.89 & -.86 & .52 & .96 & .89 & -.86 & 1 & -.18 \\
BV & .61 & .66 & .75 & .10 & .29 & .66 & -.18 & 1 \\
\hline
\end{tabular}

Keterangan :

: korelasi positif nyata

Hubungan antara parameter sifat-sifat tanah dan parameter cacing tanah pada lahan konvensional memiliki pola yang berbeda dibandingkan pada lahan organik. KPC berhubungan sangat erat nyata dengan biomassa $\left(\mathrm{r}^{2}=.998\right)$ dan $\mathrm{pH}\left(\mathrm{r}^{2}=.998\right)$ pada lahan konvensional, sedangkan hubungan KPC dengan P, C-Organik dan permeabilitas adalah erat negatif (Tabel 5). Jumlah cacing tanah pada lahan konvensional lebih rendah dibandingkan dengan lahan organik diduga tidak karena kesuburan tanah yang lebih rendah tetapi lebih disebabkan oleh penggunaan pestisida. Hasil penelitian ini sejalan dengan pernyataan Yuliprianto (2009) bahwa residu pestisida di dalam tanah dapat menurunkan secara laten pertumbuhan dan reproduksi cacing tanah.Pestisida kimia diketahui memiliki pengaruh negatif terhadap organisme dalam tanah (Rombke et al., 2007). Berdasarkan hasil wawancara dengan petani, penggunaan pestisida pada lahan konvensional sangat banyak, bahkan disaat tidak ada serangan hama, pestisida tetap digunakan. Hasil analisis ragam menunjukkan bahwa perlakuan bahan pertanian berpengaruh sangat nyata terhadap mortalitas cacing tanah (Werdhyastuti, 2018, belum dipublikasikan).
Tingginya nilai NPK pada lahanpertanian konvensional disebabkan adanya pemupukan NPK kimia. Namun, tingginya kadar NPK pada tanah pertanian konvensional tidak diikuti dengan meningkatnya kelimpahan cacing tanah dilahan tersebut. Hal ini sesuai dengan pernyataan Tiwari (1993) yang menyatakan bahwa penggunaan pupuk NPK konvensional tanpa kombinasi dengansampah organik tidak meningkatkan populasi maupun biomassa cacing tanah.

Jenis cacing yang ditemukan pada lahan organik berbeda dengan lahan konvensional. Cacing tanah yang ditemukan pada lahan organik adalah $L$. terrestris dan cacing yang ditemukan pada lahan konvensional adalah cacing $P$. corethrurus. Karakteristik morfologi kedua jenis cacing tersebut disajikan pada Tabel 6.Cacing $L$. terrestris tergolong cacing besar.Cacing ini merupakan kelompok dekomposer yang memangsa serasah organik di atas permukaan tanah.Cacing tanah $L$. terrestris dapat dikelompokkan pada tipe ekologi anesik karena cacing tanah ini mudah ditemukan pada kedalaman 0-10 cm.Cacing $P$. corethrurusmerupakan cacing jenis endogeik yang mudah ditemukan pada tanah 
dalam.Tidak seperti L. terrestris, cacing secara horizontal di dalam tanah, pemakan P.corethrurus cenderung tidak berwarna atau tanah (geofagus) dan meninggalkan kascing tidak memiliki pigmen, membuat lubang di dalam tanah.

Tabel 6. Data morfologi jenis cacing tanah pada lahan pertanian organik dan konvensional di Bedugul

\begin{tabular}{lll}
\hline & Organik & Konvensional \\
\hline Jenis & Lumbricus & Pontoscolex \\
& terrestris & corethrurus \\
Panjang $(\mathbf{c m})$ & $18-29$ & $4-9$ \\
Diameter $(\mathbf{c m})$ & 0.5 & 0.2 \\
Tipe ekologi & Aneksik & Endogeik \\
Warna Tubuh & Gelap & Terang \\
$\quad$ Anterior & Cokelat & Oranye kekuningan \\
Posterior & Hitam & Kuning kecoklatan \\
Bentuk mulut & Prolobus & Zygolobus \\
(Prostomium) & &
\end{tabular}

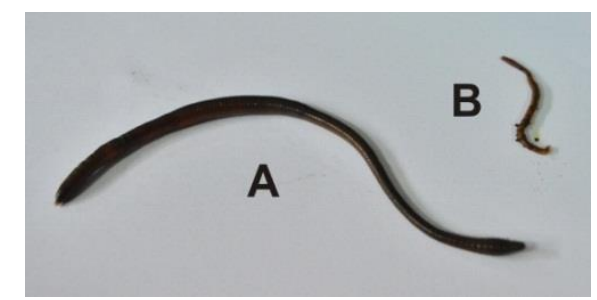

Lumbricus terrestris (A) danPontoscolex corethrurus (B)

\section{SIMPULAN}

Jumlah kepadatan populasi cacing (KPC) lebih tinggi pada lahan sayuran organik dengan total rata-rata $73 \mathrm{ekor} / \mathrm{m}^{2}$ dibandingkan dengan lahan sayuran konvensional $30 \mathrm{ekor} / \mathrm{m}^{2}$. Jenis cacing tanah yang ditemukan pada lahan sayuran organik adalah Lumbricus terrestris sedangkan pada lahan sayuran konvensional adalah Pontoscolex corethrurus. Jumlah cacing tanahpada lahan sayuran organik cenderung lebih banyak pada kedalaman 0-10 cm 89 ekor/m².sedangkanpada lahan sayuran konvensional pada kedalaman 20-30 cm dengan jumlah 45 ekor $/ \mathrm{m}^{2}$.

\section{DAFTAR PUSTAKA}

Bouche,M., 1977. Strategies Lumbriciemnes. Ecol. Bull, Stockholm 25,122-132.

Curry,J.P., 1994. Grassland Invertebrates. Chapmann \& Hall, London, 437p

Dwiastuti Sri \& Suntoro. 2009. Eksistensi Cacing Tanah Pada Lingkungan Berbagai Sistem Budidaya Tanaman Di Lahan Berkapur.Universitas Sebelas Maret, Jl. Ir.Sutami No. 36A, Surakarta.

Edward, C.A \& P.J. Bohlen. 1996. Biology and Ecology of Earthworms.London: Chapman and Hall.

Jayanthi, Sri, Retno Widhiastuti, Erni Jumilawaty. 2014. Komposisi Komunitas Cacing Tanah Pada Lahan Pertanian Organik Dan Konvensional 
ARFITA TRI MAYASARI. et al. Populasi, Biomassa dan Jenis Cacing Tanah pada Lahan...

Di Desa Raya Kecamatan

Berastagi Kabupaten Karo.

Pascasarjana Departemen Biologi FMIPA Universitas Sumatera Utara.

Kartasapoetra., A.G, Mulyani Sutedjo. 1987. Teknologi Konservasi Tanah dan Air.Cetakan ke dua.Jakarta : Bina Aksara.

Köhler, Anna-Sophie, Sebastian Wolfrum, Julia Huber, Kürt-Jurgen Hüsbergen. 2014. Earthworm abundance and species richness: contribution of farming system and habitat type. Rahmann G \&Aksoy U (Eds.). Proc. of the $4^{\text {th }}$ ISOFAR Scientific Conference. 'Building Organic Bridges', at the Organic World Congress 2014, 13-15 Oct., Istanbul, Turkey (eprint ID 23992)

Levy PE, Hale SE, and Nicoll BC.2004. Biomass expansion factors and root:shootratios for coniferous tree species in Great Britain. Forestry, 77(5:421-430.

Nuril, H, B. Paul Naiola, E. Sambas, F.Syarif, M. sudiana, J.S.Rahajoe, Suciatmih,T.Juhaeti\& Y. Suhardjono. 1999. Perubahan Bioekofisik LahanBekasPenambangan Emas di Jampang dan Metoda Pendekatannya untuk upaya reklamasi. Laporan teknik Proyek Penelitian Pengembangan dan Pendayagunaan Potensi Wilayah, tahun 1998/1999. PuslitbangBiologi LIPI.

Puslittanak.2004. Petunjuk Teknis Pengamatan Tanah.Penerbit Pusat Penelitian Tanah dan Pengembangan Tanah dan Agroklimat. Bogor.

Rombke, J., M.V.Garvia, A. Scheffezy. 2007. Effect of the fungicide benomyl on earthworms inlaboratory tests under tropical and temperate conditions. Arch.Environ Contam oxicol 53, 590-598.

Smetak, K. M., J. L. Johnson-Maynard dan J. E. Lloyd. 2007. Earthworm population density and diversity in different aged urban systems. Applied Soil Eco- logy 37: 161-168.

Subin Kalu, Madan Koirala\& Udhab Raj Khadaka.2015. Earthworm population in relation to different land use and soil characteristics.Central Department of Environmental Science, Tribhuvan University, Kirtipur, Kathmandu Nepal.Amrit Science Campus, Tribhuvan University, Thamel, Kathmandu, Nepal.

Tiwari, S. C. 1993. Effect of Organic Manure and NPK Fertilization of Eartworm Activity in an Oxisol.Biology and Fertility ofSoil. 16: 293-295.

Werdhyastuti, N.L. 2018. Sensitivitas Cacing Tanah Lokal di Kecamatan Baturiti terhadap Pupuk Organik dan Pestisida Sintetik.Skripsi.Belum dipublikasikan.

Wijayanti, L. 2007. Kelimpahan Cacing Tanah Pada Tanah Sawah Sistem Budidaya Pertanian Padi Organik dan Anorganik. Skripsi. Jurusan Pendidikan Biologi FMIPA UNY.

Yuliprianto, H. 2009. Prosiding Seminar Nasional Penelitian,Pendidikan dan Penerapan MIPA, Pendidikan Biologi, Fakultas MIPA, Universitas Negeri Yogyakarta. 